\title{
Five Simple and Low Maintenance Investing Strategies: Seeking an Automated Investing System
}

\author{
John J. Cheh ${ }^{1} \quad$ Changrae Park ${ }^{2} \quad$ Il-woon Kim ${ }^{3 *}$ \\ 1.College of Business Administration, The University of Akron, Akron, Ohio, USA \\ 2.Department of Accounting, Gangneung-Wonju National University, Gangneung, South Korea \\ 3.College of Business Administration, The University of Akron, Akron, Ohio, USA \\ *E-mail of corresponding author: ikim1@uakron.edu
}

\begin{abstract}
The purpose of the paper is to examine five different investment strategies which are known to be easily implemented by ordinary investors: (1) S\&P 500 strategy, (2) No OTC \& No ADR (NoOtcAdr) strategy, (3) Warren Buffett's stock market indicator-based strategy, (4) Federal Reserve Bank's monetary policy-based strategy, and (5) Joel Greenblatt's magic formula strategy. Among a large number of minimal maintenance strategies available, we investigate the efficacy of these five investment strategies because these strategies are extremely simple to implement and require little time commitment for investment research. Once they are set up, they will be maintenance free. Based on our findings and analysis, we propose a pair of options to retail investors, depending on their time commitment and risk tolerance level. Among five investment strategies, investors with high-risk tolerance may find merits in the Fed's monetary policy-based strategy, whereas investors with low-risk tolerance may find Buffett's stock market indicator-based strategy attractive.
\end{abstract}

Keywords: Low maintenance investing strategies; Fed funds rate; Greenblatt's magic formula; Sector rotation, Warren Buffett stock market indicator

DOI: $10.7176 /$ RJFA/11-2-01

Publication date: January $31^{\text {st }} 2020$

\section{Introduction}

The goal of this paper is not to seek an investment strategy that produces the highest alpha or abnormal returns far beyond the returns of stock market indices; but rather, it is to provide investment insights with which rank-andfile retail investors are able to gradually increase their retirement assets over time --- with a minimal amount of effort --- so that ordinary working professionals' diligent saving and prudent investment strategy over multiple decades will result in a reasonable size nest egg for their post-employment years. Thus, implementation of an automated investment system --- that requires little time demand over the course of a long investment horizon and, at the same time, brings returns on investment greater than the risk-free rate --- becomes critical for them to accumulate a sizable equity over multiple decades of their professional career.

To accomplish this objective, we examine five investment strategies that are known to be relatively simple to implement by ordinary investors who have regular jobs in industries other than the financial industry, and that require little maintenance or no maintenance, as if investing processes are automated. Among the large number of such no-maintenance investment strategies, we review five popular investment strategies: (1) S\&P 500 strategy, (2) No OTC \& No ADR (NoOtcAdr) strategy, (3) Warren Buffett's stock market indicator-based strategy, (4) Federal Reserve Bank's monetary policy-based strategy, and (5) Joel Greenblatt's magic formula strategy. All of these strategies are extremely simple to implement and require little time to invest. Thus, the strategies belong to a class of automated or no-maintenance investing systems.

In recent years, a new class of investment advisors --- often called robo advisors --- has emerged to provide automated investment advising to busy professionals to assist them in preparing for their post-employment years (Allentuck, 2017): "In the feast of financial advice offered by the wealth management industry, robo advisors are the McDonald's of financial information. Like stock brokers and professional portfolio managers, mutual fund account sales folks and the occupants of back offices at your corner bank, robo advisors suggest what kinds of investments to make. Unlike the traditional advisors, they offer a limited menu of packaged assets, mostly exchange traded funds, usually through web-based accounts. There's no hand holding for times when markets sag and the frightened flee. In that gap - call it financial theory vs. human emotion, is the difference between advising clients by the numbers and, forgive the medical metaphor, having a sit down and taking their pulse" (Allentuck, 2017).

Rank-and-file retail investors may use such automated investment services. Yet, the robo advisors' services are not free, although the fees for such services are lower than fees charged by traditional financial advisors. According to Allentuck (2017), the robots charge an advisory fee of a half of a percent on an asset of $\$ 250,000$ to $\$ 500,000$, while the service rate increases, when the assets under management are smaller than a quarter of a million dollars. The robo advisory fees, however, can add up over a professional's career; and the accumulated fees over multiple decades can become significant to ordinary rank-and-file retail investors. 
In this paper, therefore, we are proposing that retail investors use what is already available in financial market places --- to automate investing processes. In her article, La Roche (2017) made a reference on this possibility by quoting Jason Karp, the founder of Toubillion Capital: "In the last ten years, a lot of things like value, growth, dividend type investing have become betas now because the rise of passive has created a lot of ETFs where you can actually replicate all these different factors, and you recreate these returns much more cheaply than you used to be able to do,' Karp said at the same Bloomberg event." (La Roche, 2017)

To build such an automated investment system and assist rank-and-file investors to take advantage of the available financial resources, in this paper, we compare returns, standard deviations, and maximum drawdowns of the five investment strategies aforementioned --- to determine which strategy would be most suitable for retail investors. The information on the maximum drawdowns will be valuable to investors who are unsure of whether they need to move their capital out of the stock market during severely distressed market conditions. If the maximum drawdowns are extreme, even though returns on a particular strategy may be attractive, investors may not be able to psychologically follow through with the strategy over vicissitude of market conditions.

For this study, we use the Portfolio123 (P123) service that provides data and software support in analyzing data. The study period for this paper is from January $2^{\text {nd }}, 1999$ to December $31^{\text {st }}, 2016$. In P123, there are a number of ways of populating data sets for a study. These options include: All Fundamentals - USA (default), All Stocks - USA, and numerous other data sets. In this study, we use the default data set: All Fundamentals - USA.

In the following section on Motivation and Literature Review, we discuss the motivation for this paper and discuss related papers. The section in which we discuss Data and Software Support follows the previous section. In the Research Methodology and Findings section, we explain each investment strategy and its merits. In the remaining sections, we examine the robustness of the five investment strategies from the perspective of a rankand-file retail investor who does not have ample time and other resources that professional money managers and investment professionals can take advantage of. The additional resources include their expertise on the stock market, financial databases, and an understanding of recent developments from their continuing education in the investment field. In the last section, we conclude this paper with discussions on future implications of our work. After the References section, we provide an Appendix for Portfolio123's high-level computer programming code for investment strategies --- to benefit readers who may be interested in experimenting with P123 to backtest similar investment strategies.

\section{Motivation and Literature Review}

Because of robo advising (Kraft, 2017) and ETF financial offerings, public employees with 401(k)-style retirement accounts may be able to manage their own financial future without the intermediaries of public pension systems, as states are moving more state employees and teachers to self-managed 401(k)-style retirement systems. Like what happened in the private sector decades ago, more states are now closing traditional pension systems to employees in the public sector. For example, populous states like Florida, Georgia, Michigan and Pennsylvania are fundamentally restructuring their traditional public retirement systems for state employees. The states are moving more employees --- including teachers --- to self-managed retirement systems that are blended pension \& 401(k)-style (or hybrid) systems and/or 401(k)-style systems --- with an ultimate goal of moving the majority of state employees to 401(k)-style systems that are prevalent in the private sector's retirement systems for employees (Dunkelberger, 2017; VanMetre, 2014; Eggert, 2017a; Eggert, 2017b; Iasevoli, 2017; Oosting and Gerstein, 2017; Dabrowski and Klingner, 2017b; Thompson, 2017). According to Lobosco (2017), Pennsylvania will be the ninth state to replace the pension with a hybrid retirement plan that is a component of the 401(k)-style accounts for workers.

This fundamental shift in the large states' politicians' thinking on retirement policies from traditional pension systems to 401(k)-style self-managed retirement systems may coincide with the dramatic increase in average lifespan of retirees (Suzman and Beard, 2015), and the forward-thinking politicians' efforts in shifting investment risk from taxpayers to public workers. This is similar to what motivated the private sector to move away from traditional pension systems --- to reduce taxpayers' unreasonable burdens on financing public employees' retirement.

Without such adjustments, public pension liabilities become too large for the taxpayers to bear, while the public pension liabilities are diverting an increasing portion of state tax revenues away from investing into their critical infrastructures such as education, health, security, and other public services, as we witnessed in states, like Illinois, that are struggling with a long winding road of public pension reform that has been taking a toll on the states' economies. The slowness of Illinois' pension reform process has been negatively affecting its economy (Dabrowski and Klingner, 2017a).

As more employees are moving from traditional pension systems to self-managed $401(\mathrm{k})$-style retirement systems, it has become essential for these employees to know how to manage their tax-deferred retirement accounts, although they have a full-time job that leaves little time to manage their investment assets. Therefore, for this type of retail investor and busy working professional, there is a strong need for a simple and easily executable 
investment strategy that requires little or no maintenance.

To respond to this type of retail investor, new investment advising services such as a robo-advisory service have emerged (Verhage and Chiglinksy, 2017). Yet, such services are not free, although they are cheaper than fees charged for traditional investment advisory services. Furthermore, investors still need to know enough about investing to make prudent choices to automate stock investment processes.

One approach of automating investment processes is to take advantage of already existing automated investing systems; and this is recognized by money managers like Jason Karp, the founder of Tourbillion Capital (La Roche, 2017). This approach does not require any commercial robo-advising services nor does it need to hire computer programmers to create an automated investing system with the aid of computer languages such as Python or EasyLanguage (Pruitt, 2016). For example, index funds, mutual funds, and exchange traded funds (ETFs) are automated investing systems that are already available to investors. All investors have to do is choose one of the funds or a combination of such funds. To accomplish this objective, however, rank-and-file retail investors need to know which funds would be most appropriate for them --- in terms of reasonable returns on their investment, risk level, and time to commit. To address this issue of finding a simpler investment strategy with little or no maintenance, in this paper, we consider five simple investment strategies, which will be discussed in detail in the Data \& Methodology and Findings sections.

\section{Data and Software Support}

To examine the five investment strategies, first, we will need to have accounting, stock market, and economics data. The data requirements depend on each investment strategy, and the five investment strategies require multiple data sets. Furthermore, to carry out our research project as accurately and efficiently as possible, with the reduction or minimization of human errors, we searched several research data and software services. Among data sets and software supports that we considered, we found that Portfolio123 (P123) would meet our research project's data and software support requirements. In this paper, therefore, we use data provided by P123. Standard \& Poor's Capital IQ and Interactive Data provide data for P123. Furthermore, we also use economic data from the Federal Reserve Economic Data in St. Louis Fed often called FRED (FRED, 2017) via P123.

P123 offers various statistical metrics for comparing the performance of multiple investment strategies. The service is ideal for stock investors who wish to test various investment strategies; it provides financial data and various tools to create customized investment decision rules for empirically testing various hypotheses on investment strategies. Taking advantage of this facility, we examine the efficacy of each investment strategy, using the high-level computer programming facilities in P123. In backtesting each strategy, we used P123 data as of December $31^{\text {st }}, 2016$, set the date of data availability as of December $31^{\text {st }}, 2017$, and used All Fundamentals USA as the universe of data. We used the study period of 17 years from January $2^{\text {nd }}, 1999$ to December $31^{\text {st }}, 2016$ to backtest each strategy.

\section{Research Methodology and Findings}

In this section, we explain our research methodology, discuss five simple investment strategies, and share with readers our findings.

\subsection{S\&P 500 Strategy}

In this simple strategy, investors merely buy and hold an S\&P 500 index fund such as Vanguard S\&P 500 ETF (Frankel, 2017). Warren Buffett advocates this simple investment strategy to ordinary investors who do not have the time, resources, and/or investment expertise to devote to full-time investing activities (Frankel, 2017; Gillies, 2017). Below are quotes from the two authors from their articles.

"Buffett's logic is that someone who invests in the S\&P500 index fund, by definition, will match the market's performance. On the other hand, 'active investors' as a group will also deliver average investment performance over time -- that is, some managers' investments will do well, and others won't. However, when you add in the cost of actively managed investment options, particularly hedge funds, the result is that the average hedge fund will underperform the market." (Frankel, 2017) "Most employer-run 401(k) retirement plans offer multiple mutual funds with different assets strategies, but Buffett warned against going with those options, saying 'you'll do very well with an S\&P index.'" (Gillies, 2017)

The returns of S\&P 500 during the study period will be presented when other techniques are discussed, and the average returns of S\&P 500 companies that represent the largest American companies will be used as the benchmark to the returns of other strategies for the purpose of comparison.

\subsection{No OTC \& No ADR (NoOtcAdr) Strategy}

This strategy is similar to the S\&P 500 index strategy, except that it embraces all stocks in the universe of P123 that we mentioned earlier, excluding over the counter (OTC) stocks and American Depository Receipt (ADR) stocks out of the stocks in the default universe data set in P123: All Fundamentals - USA. By going through a list 
of ETFs available in stock markets from various ETF vendors, investors will be able to find multiple ETFs to simulate this particular strategy. For example, investors may be able to construct a portfolio which consists of multiple ETFs of USA small-cap, mid-cap and large-cap stocks so that they exclude OTC and/or penny stocks out of their portfolio.

In this paper, we examine the NoOctAdr strategy with three different rebalance frequencies (i.e., monthly, quarterly and yearly), and the results are presented in Panel A of Exhibit 1 with a supporting chart in Panel B. Yearly rebalancing produces the highest return of $16.3 \%$ among them, but it also has the lowest maximum drawdown of $-60.76 \%$. The yearly rebalancing generates the highest Sharpe ratio of 0.73 and Sortino ratio of 1.05 , among the three different rebalancing frequencies; and the yearly rebalancing is significantly better than the other rebalancing frequencies for the risk measures. Since the Sharpe ratio is less than one, this strategy's return is less proportional to the risk taken. Yet, the strategy's Sharpe ratio problem is somewhat mitigated because its Sortino ratio is greater than one. Thus, this strategy's return is slightly better, proportional to the risk taken, when there are downside movements.

Exhibit 1: Comparison of No-OtcAdr strategy with S\&P 500 strategy

Panel A (Highest return rebalancing frequency statistics are highlighted with a bold font.)

\begin{tabular}{|l|l|l|l|l|l|}
\hline $\begin{array}{l}\text { Strategy (Rebalance } \\
\text { Frequency) }\end{array}$ & Annualized & \multirow{2}{*}{ Max. Drawdown } & \multicolumn{3}{|l|}{ Risk Statistics (Monthly Period) } \\
\cline { 4 - 6 } & Return & & Sharpe & Sortino & S. D. \\
\hline NoOtcAdr (Monthly) & $12.96 \%$ & $-63.40 \%$ & 0.58 & 0.82 & $21.79 \%$ \\
\hline NoOtcAdr (Quarterly) & $10.97 \%$ & $-63.96 \%$ & 0.51 & 0.71 & $20.78 \%$ \\
\hline NoOtcAdr (Yearly) & $\mathbf{1 6 . 3 0 \%}$ & $\mathbf{- 6 0 . 7 6 \%}$ & $\mathbf{0 . 7 3}$ & $\mathbf{1 . 0 5}$ & $\mathbf{2 1 . 0 6 \%}$ \\
\hline S\&P500 (All Three) & $3.42 \%$ & $-57.00 \%$ & 0.17 & 0.22 & $15.35 \%$ \\
\hline
\end{tabular}

Panel B: Chart with Yearly Rebalance Frequency

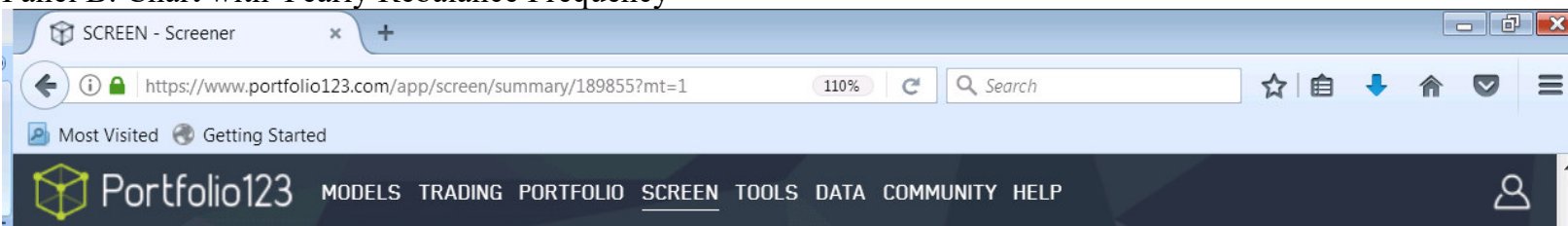

\section{$\leftrightarrow$ BACKTEST RESULTS}

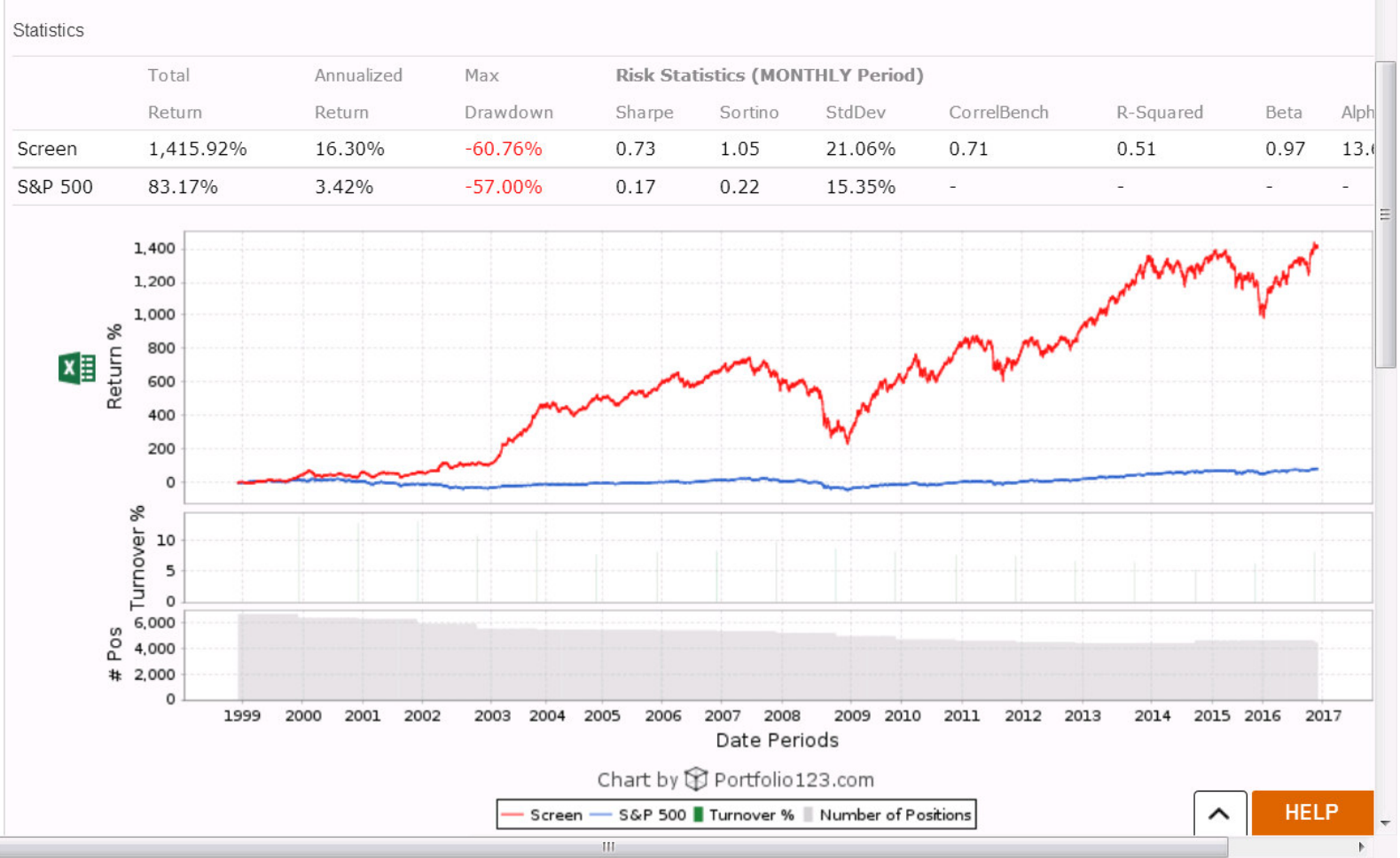

This NoOctAdr strategy, in all rebalancing frequencies, performed significantly better than the S\&P 500 index fund with a wide margin in annual returns as shown in Panel B. Nevertheless, the S\&P 500 strategy's maximum drawdown is lower than that of the NoOtcAdr strategy in any rebalancing frequency, although the differences are 
not significant. On the other hand, the S\&P 500 strategy's Sharpe ratio of 0.17 and Sortino ratio of 0.22 are much smaller than the NoOctAdr strategy in any rebalancing frequency; and both are below 0.5. The standard deviation of the S\&P 500 strategy is lower than that of the NoOctAdr strategy among all three rebalancing frequencies.

\subsection{Buffett Market Indicator-based Strategy}

In Fortune Magazine (1999, 2001, Buffett and Loomis), Buffett wrote about how he would assess the over- and under-valuation of stock markets. According to him, the ratio of market capitalization over gross national product (GNP) would serve as a good proxy for assessing the stock market. In this paper, let us call the ratio the Buffett market indicator.

Mislinski (2017) maintains a web site on the Buffett market indicator, using the most updated data. The variables that he uses for the indicator are corporate equities and nominal quarterly gross domestic product (GDP). For the market capitalization, he uses the Wilshire 5000 stock market index. For our study, we use the ratio of Russell 3000 index over GDP/1000 as the Buffett market indicator. When the ratio is less than 50, investors put their capital into the S\&P 500 index fund; in other situations, they invest in stocks in the utilities sector. The utilities sector is known to have fared best during the stock market downturn in 2011 (Doorn, 2015). The usefulness of Buffett's stock market indicator is that investors would be cautioned in allocating their capital into the stock market when the stock market valuation is extended beyond GDP, and investors can find stock investing more attractive when the stock market is undervalued.

Using the indicator 50 as the right number for Buffett's stock market indicator helps conservative investors decide whether they want to stay with the S\&P 500 index fund or an ETF fund that consists of utilities sector stocks. Exhibit 2 presents the information about Russell 3000 market capitalization, GDP/1000, and Buffet's stock market indicator. When the indicator is less than 50, stock prices are fairly valued; hence, investors prefer to stay with S\&P 500 stocks. On the other hand, when the indicator exceeds 50, investors would be better off in staying with the most conservative defensive stocks such as utilities sector stocks.

Exhibit 2: Russell 3000 Market Capitalization, GDP/1000, and Buffett's Stock Market indicator

\begin{tabular}{|l|l|l|l|}
\hline Year & $\begin{array}{l}\text { Rusell 3000 Market Capitalization } \\
\text { (R3TMC) (in Billions) }\end{array}$ & $\begin{array}{l}\text { GDP/1000 (TGDP) } \\
\text { (in Trillions) }\end{array}$ & $\begin{array}{l}\text { Buffett market indicator: } \\
\text { R3TMC/TGDP }\end{array}$ \\
\hline $1 / 4 / 1999$ & 664.27 & 11.77 & 56.43 \\
\hline $1 / 3 / 2000$ & 793.31 & 12.32 & 64.37 \\
\hline $1 / 3 / 2001$ & 701.23 & 12.68 & 55.31 \\
\hline $1 / 3 / 2002$ & 637.27 & 12.71 & 50.16 \\
\hline $\mathbf{1 / 3 / 2 0 0 3}$ & $\mathbf{5 0 5 . 1 8}$ & $\mathbf{1 2 . 9 6}$ & $\mathbf{3 8 . 9 7}<\mathbf{5 0}$ \\
\hline $\mathbf{1 / 3 / 2 0 0 5}$ & $\mathbf{6 9 3 . 6 3}$ & $\mathbf{1 3 . 9 5}$ & $\mathbf{4 9 . 7 2}<\mathbf{5 0}$ \\
\hline $1 / 3 / 2006$ & 723.31 & 14.37 & 50.32 \\
\hline $1 / 3 / 2007$ & 822.13 & 14.72 & 55.86 \\
\hline $1 / 3 / 2008$ & 837.17 & 14.99 & 55.84 \\
\hline $\mathbf{1 / 5 / 2 0 0 9}$ & $\mathbf{5 3 6 . 2 6}$ & $\mathbf{1 4 . 5 8}$ & $\mathbf{3 6 . 7 9}<\mathbf{5 0}$ \\
\hline $\mathbf{1 / 4 / 2 0 1 0}$ & $\mathbf{6 5 3 . 1 3}$ & $\mathbf{1 4 . 5 4}$ & $\mathbf{4 4 . 9 1 < 5 0}$ \\
\hline
\end{tabular}

Note: The data for some years is not presented here for conciseness.

With this background, we examine the Buffett market indicator-based strategy with three different rebalancing frequencies and find that yearly rebalancing produced the highest return of $12.11 \%$ among them as shown in Panel A of Exhibit 3. Its maximum drawdown was also the lowest, compared with the two other rebalancing frequencies. The yearly rebalancing generates the highest Sharpe ratio and Sortino ratio, among the three different rebalancing frequencies. The Sharpe ratio of less than one for the yearly rebalancing strategy indicates that its risk-adjusted return is not as good as it could be for higher Sharpe ratios greater than one. Nevertheless, the Sortino ratio of 1.05 for the yearly rebalancing is the highest among all three rebalancing frequencies; and it is greater than 1. As a result, this yearly rebalancing will be less likely affected from negative volatility than the two other rebalancing frequencies. The standard deviation of the yearly rebalancing is also the lowest among the three rebalancing frequencies.

Exhibit 3: Comparison of Warren Buffett's Market-indicator-based Strategy with S\&P 500 Strategy Panel A (Highest return rebalancing frequency statistics are highlighted with a bold font)

\begin{tabular}{|l|l|l|l|l|l|}
\hline $\begin{array}{l}\text { Strategy (Rebalance } \\
\text { Frequency) }\end{array}$ & $\begin{array}{l}\text { Annualized } \\
\text { Return }\end{array}$ & \multirow{2}{*}{ Max. Drawdown } & \multicolumn{3}{|l|}{ Risk Statistics (Monthly Period) } \\
\cline { 4 - 6 } & & & Sharpe & Sortino & S. D. \\
\hline Buffett (Monthly) & $11.33 \%$ & $-52.50 \%$ & 0.64 & 0.86 & $16.71 \%$ \\
\hline Buffett (Quarterly) & $11.81 \%$ & $-55.22 \%$ & 0.67 & 0.89 & $16.65 \%$ \\
\hline Buffett (Yearly) & $\mathbf{1 2 . 1 1 \%}$ & $-\mathbf{4 4 . 7 8 \%}$ & $\mathbf{0 . 7 6}$ & $\mathbf{1 . 0 5}$ & $\mathbf{1 4 . 5 6 \%}$ \\
\hline S\&P500 (All Three) & $3.42 \%$ & $-57.00 \%$ & 0.17 & 0.22 & $15.35 \%$ \\
\hline
\end{tabular}


Panel B: Chart with Yearly Rebalance Frequency

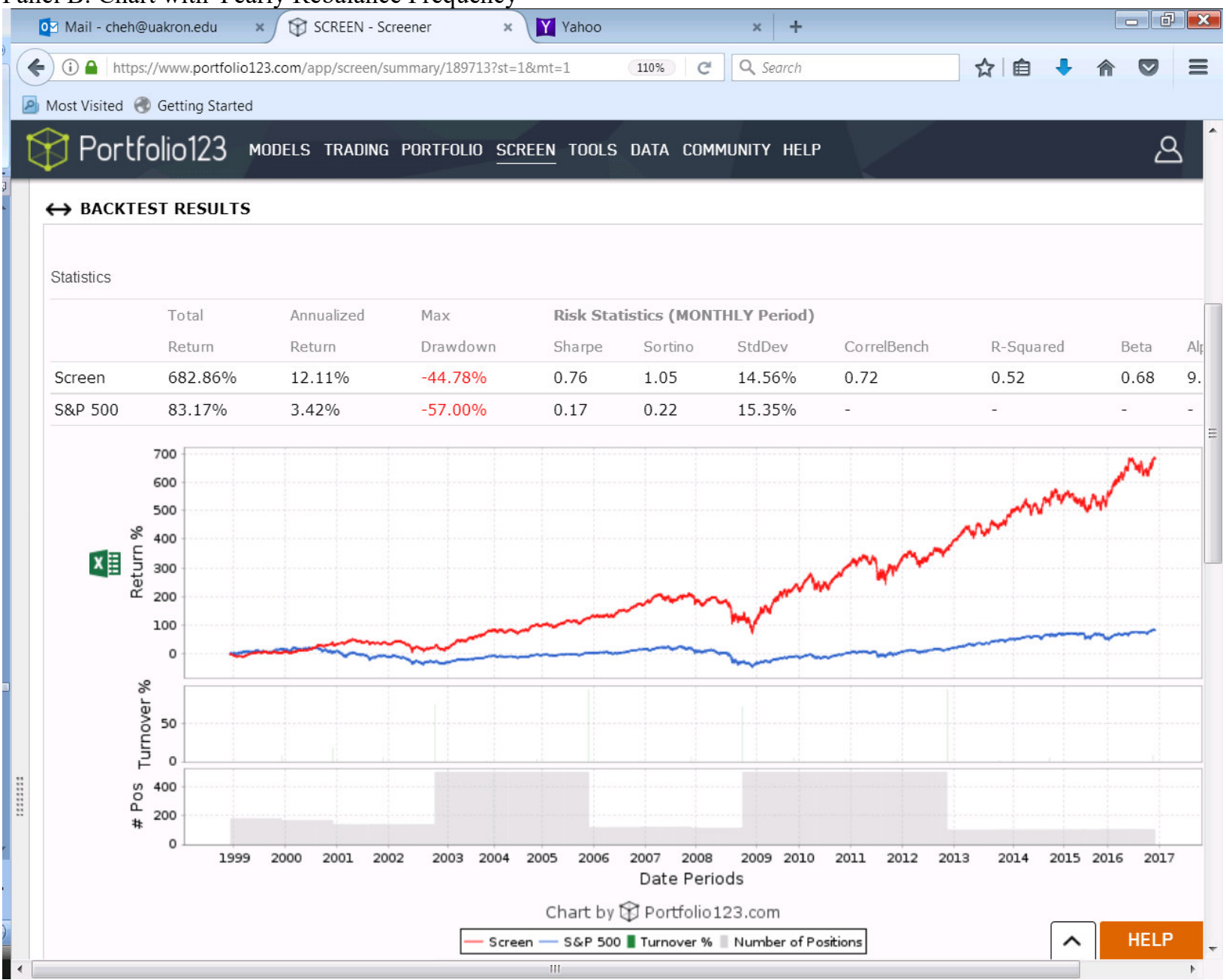

This Buffett market indicator-based strategy in all rebalancing frequencies performed much better than the S\&P 500 index fund with a wide margin in annual returns, as shown in Panel B. Furthermore, the S\&P 500 strategy's maximum drawdown is higher than that of the Buffett market indicator-based strategy in any of the three rebalancing frequencies, although the differences are not significant. On the other hand, the S\&P 500 strategy's Sharpe ratio of 0.17 and Sortino ratio of 0.22 are much smaller than those of the Buffett market indicator-based strategy in any rebalancing frequency; and both are below 0.5. The standard deviation of the S\&P 500 strategy is higher than that of the Buffett market indicator-based strategy for the yearly rebalancing frequency.

\subsection{Federal Reserve Bank (Fed)'s Monetary Policy-based Strategy}

The investment strategy proposed by Conover, Jensen, Johnson, and Mercer (2008a) was simple but very powerful. A thoughtful examination of Exhibit 4 reveals the interaction between the Fed's federal fund rates and recessions. Conover et al. (2008a) also recognized the play between the two variables and decided to examine the interplay in detail. 
Exhibit 4: Effective Federal Funds Rate (Fedfunds, 2017)

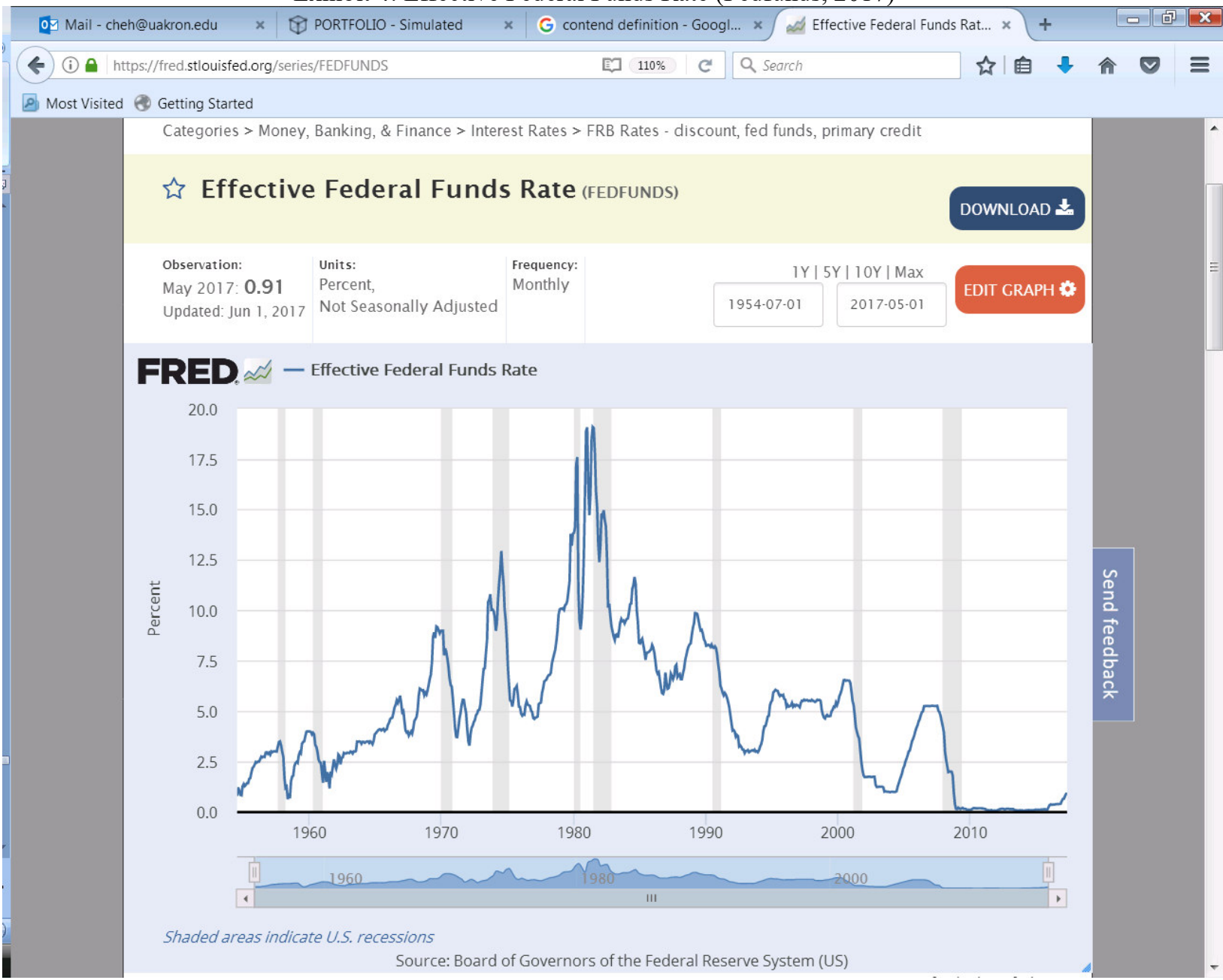

They observed that it would be advantageous for investors to move their capital from cyclical stocks to noncyclical stocks when the Fed starts raising federal fund rates, leading the economy to contract. Then, the process is reversed when the Fed starts lowering the rates to stimulate the economy and expand it.

Nevertheless, this interplay is far more complex that it appears. In this paper, we do not delve into explaining the intricacy of interaction among a number of economic variables, and interested readers may explore further by examining economists' works (Dagnino, 2001; Kashkari, 2007). In the summary of their paper (Conover et al., 2008 b, p. 67), the authors note that, relative to other indicators, a sector rotation strategy based on monetary shifts has four advantages: (1) lower trading costs, (2) an objective and easily identified indicator, (3) the ability to identify monetary policy shifts on an ex ante basis, and (4) monetary policy shifts empirically linked to patterns in underlying macroeconomic measures.

This recognition is consistent with our objective of finding a simple investment strategy that requires little maintenance. In the short write-up of their published paper (Conover et a., 2008a), the authors discussed their simple and elegant powerful investment strategy as follows:

"The sector rotation portfolio strategy is implemented by rebalancing to and from a defensive (aggressive) position when Fed monetary policy changed from restrictive to expansive, and vice versa. In constructing a sector rotation portfolio, the authors equally weight the six cyclical sectors during the expansive monetary policy period and the four noncyclical sectors during the restrictive monetary policy period on an ex ante basis." (Conover et al., 2008b, p. 67) Their investment approach to stock investing is to recognize an advantage when investors shift their capital from cyclical sectors to non-cyclical (defensive) sectors when the Fed starts raising federal funds rates to restrict the economy by taking a defensive position. When the Fed starts cutting federal fund rates --- according to the authors' investment strategy --- investors may take an aggressive stance by shifting their capital to stocks in cyclical sectors.

In our paper, we are taking an opposite approach to what Conover et al. (2008a and 2008b) did in switching between cyclical and defensive groups of stocks. In this approach, the authors moved capital from defensive sectors to cyclical sectors when the Fed lowered federal funds rates --- to expand or stimulate the economy.

In Exhibit 4, we recognize that the Fed often does not lower federal funds rates until the stock market is about 
to collapse. In this situation for investors, it makes more sense to move their capital to conservative stocks such as defensive stocks instead of cyclical stocks which are falling faster than defensive stocks. Therefore, we are moving capital to defensive stocks when the Fed is lowering federal fund rates; and we move capital to cyclical stocks, when federal fund rates are rising or flat, because of the Fed's monetary policy to contract the economy from getting too heated or curb potential inflationary pressure. It can also be noticed that, under the Fed's restrictive monetary policy, federal funds rates do not necessarily rise steadily nor fall in a stable fashion, although the increases or decreases in the rate are far more stable than stock price volatility. As a result, investors will experience whipsaws in shifting capital between cyclical stocks and non-cyclical stocks.

Nevertheless, Conover et al. (2008a) did not address this issue of whipsaws. Instead, they picked the investment dates with the following guidelines: "To ensure that the sector rotation strategy avoids any look-ahead bias and can be practically implemented on an ex-ante basis, portfolio returns are measured starting two days after an announced policy change and continue until one day after the subsequent policy change. This represents a conservative approach, as it assumes investment managers are unable to capture any announcement-period reaction associated with a shift in monetary policy. This approach is an improvement over those previous rotation studies that were implemented on an ex-post basis." (Conover et al., 2008a, p. 6).

It is not clear whether or not starting two days after an announced policy change will solve the whipsaw problem. To address the issue of whipsaws in this paper, we use the positive (plus) directional movement (+DM) and negative (minus) directional movement (-DM) as the guidelines for investors to decide when to shift their capital. These $+\mathrm{DM}$ and $-\mathrm{DM}$ are widely used indicators in technical analysis, which are often used with the average directional index (ADX) (Stockcharts.com, 2017).

To implement Conover et al.'s investment strategy, investors need to classify various sectors in the economy into two groups of non-cyclical sectors (defensive) and cyclical sectors (cyclical) using the classification guidelines from MCSI (2014), as presented in Exhibit 5. We put various sectors into two groups, as shown in Exhibit 5. Each sector weighs $20 \%$ in the entire portfolio, since we are using five sectors in each of the defensive and cyclical groups.

Exhibit 5: Classification of Noncyclical (Defensive) and Cyclical (Aggressive) Sectors,

Using MSCI Inc.'s Guidelines on Construction of Defense and Aggressive Sectors Indexes (MSCI, 2014)

\begin{tabular}{|c|c|c|}
\hline Code & Economic Sector & Noncyclicals (Defensive)/Cyclicals \\
\hline 10 & Energy & Noncyclicals (Defensive) \\
\hline 30 & Consumer Staples & Noncyclicals (Defensive) \\
\hline 35 & Health Care & Noncyclicals (Defensive) \\
\hline 50 & Telecommunication Services & Noncyclicals (Defensive) \\
\hline 55 & Utilities & Noncyclicals (Defensive) \\
\hline 15 & Materials & Cyclicals \\
\hline 20 & Industrials & Cyclicals \\
\hline 25 & Consumer Discretionary & Cyclicals \\
\hline 40 & Financials & Cyclicals \\
\hline 45 & Information Technology & C \\
\hline
\end{tabular}

In this paper, we examine this Fed strategy with three different rebalance frequencies, and the results reported in Panel A of Exhibit 6 show that yearly rebalancing produces the highest return of $25.93 \%$ among them, but it also has the lowest max drawdown of -52.93 . The yearly rebalancing generates the highest Sharpe ratio of 0.84 and Sortino ratio of 1.61, among three different rebalancing frequencies, and the yearly rebalancing is significantly better than the other rebalancing frequencies for the risk measures.

Exhibit 6: Comparison of Fed's Monetary Policy-based Investment Strategy with S\&P 500 Strategy Panel A (Highest return rebalancing frequency statistics are highlighted with a bold font.)

\begin{tabular}{|l|l|l|l|l|l|}
\hline Strategy (Rebalance & Annualized Return & Max. & \multicolumn{3}{|l|}{ Risk Statistics (Monthly Period) } \\
\cline { 4 - 6 } Frequency) & & Drawdown & Sharpe & Sortino & S. D. \\
\hline Fed (Monthly) & $12.45 \%$ & $-58.63 \%$ & 0.47 & 0.78 & $29.03 \%$ \\
\hline Fed (Quarterly) & $13.64 \%$ & $-53.76 \%$ & 0.63 & 0.89 & $20.65 \%$ \\
\hline Fed (Yearly) & $\mathbf{2 5 . 9 3 \%}$ & $\mathbf{- 5 2 . 9 3 \%}$ & $\mathbf{0 . 8 4}$ & $\mathbf{1 . 6 1}$ & $\mathbf{3 0 . 1 2 \%}$ \\
\hline S\&P500 (All Three) & $3.42 \%$ & $-57.00 \%$ & 0.17 & 0.22 & $15.35 \%$ \\
\hline
\end{tabular}


Panel B: Chart with Yearly Rebalance Frequency

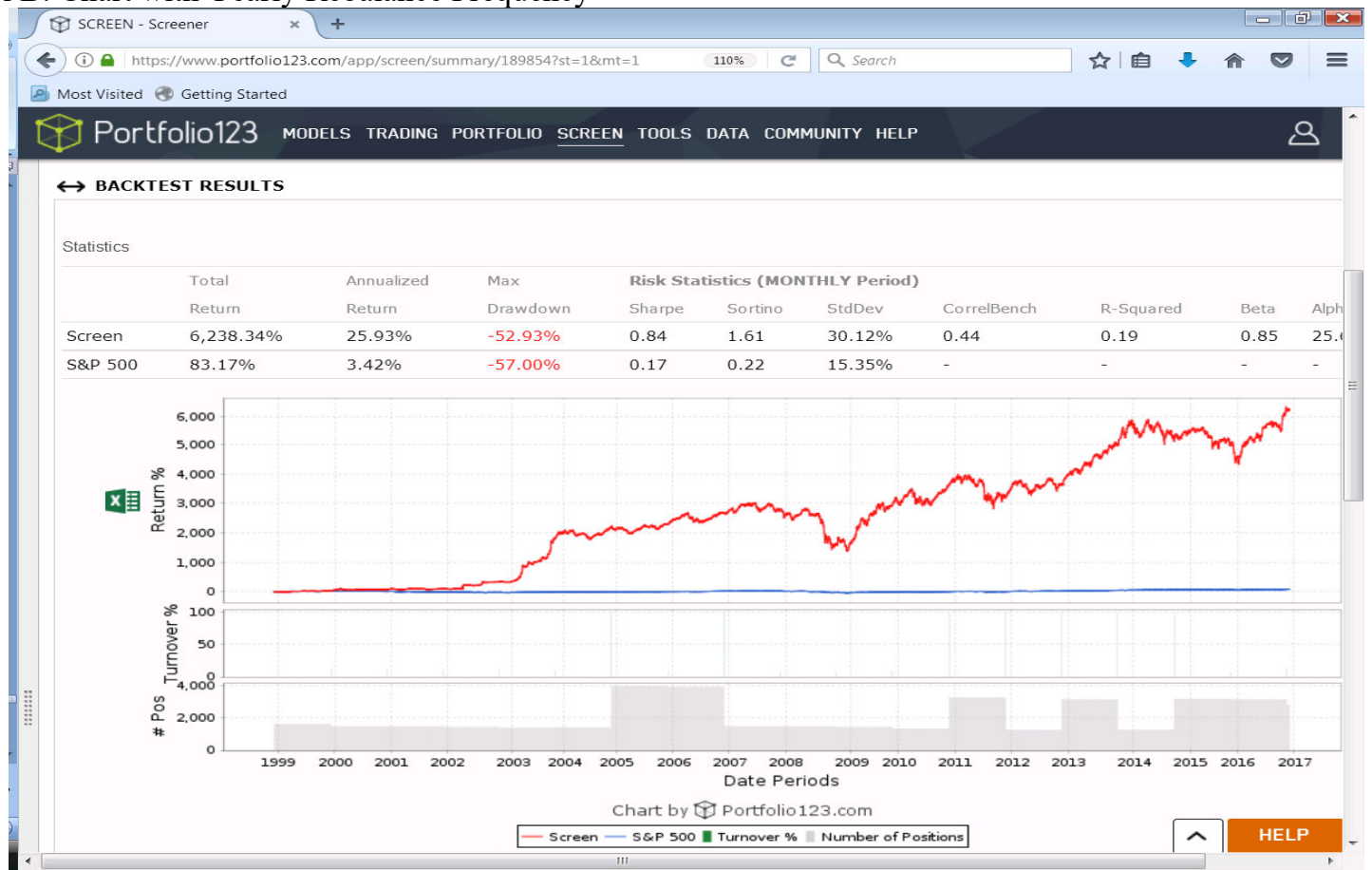

The Fed's monetary policy-based strategy in all rebalancing frequencies performed much better than the S\&P 500 index fund with a wide margin in annual returns, as shown in Panel B. Furthermore, the S\&P 500 strategy’s maximum drawdown is higher than that of the Fed strategy in quarterly and yearly rebalancing frequencies, although the differences are not significant. On the other hand, the S\&P 500 strategy's Sharpe ratio of 0.17 and Sortio ratio of 0.22 are much smaller than the Fed strategy in any rebalancing frequency; and both are below 0.5 . However, the standard deviation of the S\&P 500 strategy is lower than that of the Fed strategy for all three rebalancing frequencies.

\subsection{Joel Greenblatt's Magic Formula Strategy}

As a hedge fund manager and professor, Joel Greenblatt $(1999,2017$ a) achieved national prominence when he wrote an influential book titled, "You can be a stock market genius". Since he later found that the investment strategies introduced in the book were too complex for ordinary investors, he decided to share with retail investors a far simpler investment strategy that he called "Magic Formula" in his book titled, "The little book that beats the market" published in 2006. In this paper, we use the stock selection rules that P123 created to simulate Greenblatt's magic formula investment strategy.

As is listed in Exhibit 7, Greenblatt's simple investment strategy uses a few variables. To make rank-and-file retail investors' jobs easier, he even provides a free website for the investors to find stocks that satisfy his investment guidelines (Greenblatt, 2017b).

Exhibit 7: Greenblatt's Magic Formula Investment Strategy Implemented in P123

\begin{tabular}{|l|l|}
\hline Item & Conditions \\
\hline Screen: Liquidity Filter & No OTC stocks \\
\hline Screen: Market Cap & $>=\$ 50$ million \\
\hline Screen: Additional Filters & No ADRs, finance stocks or real estate stocks \\
\hline $\begin{array}{l}\text { Screen: Return on } \\
\text { Investment (ROI) }\end{array}$ & Five-year ROI $>=$ a percentile rank of 65 \\
\hline $\begin{array}{l}\text { Ranking System: Return on } \\
\text { Capital }\end{array}$ & $\begin{array}{l}50 \% \text { of total } \\
{[\text { Operating Income After Depereciation (also refered to as Earnings before }} \\
\text { Interest and Taxes or EBIT) divided by Tangible Capital (net plant plus accounts } \\
\text { receivable plus inventories) }]\end{array}$ \\
\hline $\begin{array}{l}\text { Ranking System: Earnings } \\
\text { Yield }\end{array}$ & $\begin{array}{l}\text { [Operating Income After Depreciation divided by Enterprise Value (Market } \\
\text { Capitalization plus Total Debt minus Cash)] }\end{array}$ \\
\hline Implementation & $\begin{array}{l}\text { The models was developed under the assumption that 15 stocks (those that pass } \\
\text { the screen and rank highest under our Joel Greenblatt ranking system) would be } \\
\text { selected and that the selections would be updated every four weeks. }\end{array}$ \\
\hline
\end{tabular}


We examine Greenblatt's strategy with 3 different rebalancing frequencies, and have found that monthly rebalancing produces the highest return of $21.48 \%$ among them, but it also has the lowest max drawdown of 53.84, as reported in Panel A of Exhibit 8. The monthly rebalancing generates the highest Sharpe ratio of 0.88 and Sortino ratio of 1.29, among three different rebalancing frequencies; and the monthly rebalancing is better than other rebalancing frequencies for the risk measures.

Exhibit 8: Comparison of Greenblatt's Magic Formula Investment Strategy with S\&P 500 Strategy Panel A (Highest return rebalancing frequency statistics are highlighted with a bold font.)

\begin{tabular}{|l|l|l|l|l|l|}
\hline Strategy (Rebalance Frequency) & Annualized Return & \multirow{2}{*}{ Max. Drawdown } & \multicolumn{3}{l|}{ Risk Statistics (Monthly Period) } \\
\cline { 4 - 7 } & & & Sharpe & Sortino & S. D. \\
\hline Greenblatt (Monthly) & $\mathbf{2 1 . 4 8 \%}$ & $\mathbf{- 5 3 . 8 4 \%}$ & $\mathbf{0 . 8 8}$ & $\mathbf{1 . 2 9}$ & $\mathbf{2 2 . 8 8 \%}$ \\
\hline Greenblatt (Quarterly) & $14.58 \%$ & $-54.10 \%$ & 0.61 & 0.91 & $23.64 \%$ \\
\hline Greenblatt (Yearly) & $15.83 \%$ & $-59.81 \%$ & 0.70 & 0.97 & $21.80 \%$ \\
\hline S\&P500 & $3.42 \%$ & $-57.00 \%$ & 0.17 & 0.22 & $15.35 \%$ \\
\hline
\end{tabular}

Panel B: Chart with Yearly Rebalance Frequency

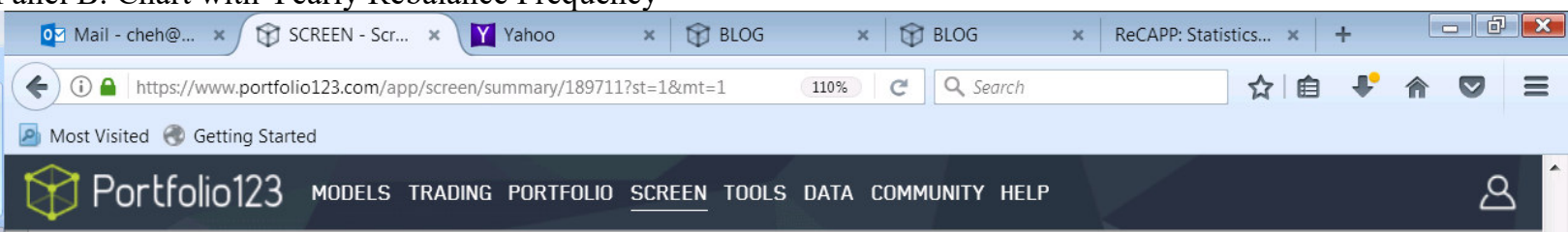

$\leftrightarrow$ BACKTEST RESULTS

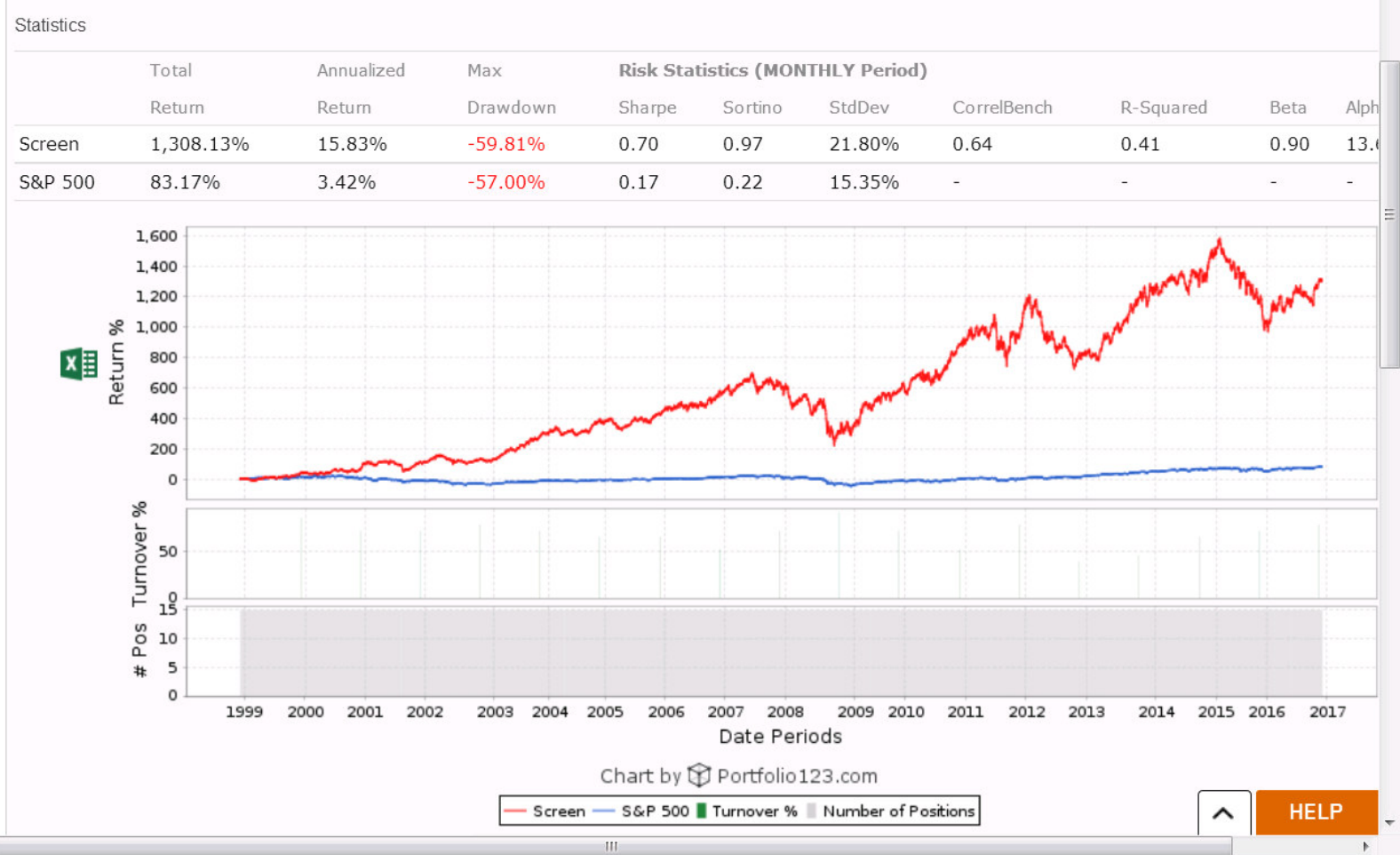

Greenblatt's strategy in all rebalancing frequencies performed much better than the S\&P 500 index fund with a wide margin in annual returns as shown in Panel B. Furthermore, the S\&P 500 strategy's maximum drawdown is higher than that of the Fed strategy in all three rebalancing frequencies, although the differences are not significant. On the other hand, the S\&P 500 strategy's Sharpe ratio of 0.17 and Sortino ratio of 0.22 are much smaller than Greenblatt's strategy in any rebalancing frequency; and both are below 0.5. The standard deviation of the S\&P 500 strategy, however, is lower than that of Greenblatt's strategy for all three rebalancing frequencies.

\section{Robustness Analysis}

In the previous section of this paper, we discussed each investment strategy and shared with readers our findings on returns and risk statistics. Based on our findings and analysis as summarized in Exhibit 9, we propose multiple paths to retail investors, depending on their time commitment and risk tolerance level. Among five investment 
strategies, investors with high-risk tolerance may find merits in the Fed's monetary policy based strategy (Panel A), whereas investors with low-risk tolerance may prefer Buffett's stock market indicator-based strategy (Panel B).

Exhibit 9: Comparison of Five Investment Strategies

Panel A (Highest return statistics are highlighted with a bold font.)

\begin{tabular}{|l|l|l|l|l|l|}
\hline $\begin{array}{l}\text { Strategy (Best Rebalance } \\
\text { Frequency) }\end{array}$ & $\begin{array}{l}\text { Annualized } \\
\text { Return }\end{array}$ & \multirow{2}{*}{$\begin{array}{l}\text { Max. } \\
\text { Drawdown }\end{array}$} & & \multicolumn{3}{|l|}{ Risk Statistics (Monthly Period) } \\
\cline { 5 - 7 } & Sharpe & Sortino & S. D. \\
\hline NoOtcAdr (Yearly) & $16.30 \%$ & $-60.76 \%$ & 0.73 & 1.05 & $21.06 \%$ \\
\hline Buffett (Yearly) & $\mathbf{1 2 . 1 1 \%}$ & $\mathbf{- 4 4 . 7 8 \%}$ & $\mathbf{0 . 7 6}$ & $\mathbf{1 . 0 5}$ & $\mathbf{1 4 . 5 6 \%}$ \\
\hline Fed (Yearly) & $\mathbf{2 5 . 9 3 \%}$ & $\mathbf{- 5 2 . 9 3 \%}$ & $\mathbf{0 . 8 4}$ & $\mathbf{1 . 6 1}$ & $\mathbf{3 0 . 1 2 \%}$ \\
\hline Greenblatt (Monthly) & $21.48 \%$ & $-53.84 \%$ & 0.88 & 1.29 & $22.88 \%$ \\
\hline S\&P500 (All Three) & $3.42 \%$ & $-57.00 \%$ & 0.17 & 0.22 & $15.35 \%$ \\
\hline
\end{tabular}

Panel B: With Worst Rebalance Frequency (Highest return statistics are highlighted with a bold font.)

\begin{tabular}{|l|l|l|l|l|l|}
\hline $\begin{array}{l}\text { Strategy (Worst Rebalance } \\
\text { Frequency) }\end{array}$ & $\begin{array}{l}\text { Annualized } \\
\text { Return }\end{array}$ & \multirow{2}{*}{$\begin{array}{l}\text { Max. } \\
\text { Drawdown }\end{array}$} & & \multicolumn{2}{l|}{ Risk Statistics (Monthly Period) } \\
\cline { 5 - 7 } & Sharpe & Sortino & S. D. \\
\hline Buffett (Monthly) & $10.97 \%$ & $-63.96 \%$ & 0.51 & 0.71 & $20.78 \%$ \\
\hline Fed (Monthly) & $\mathbf{1 1 . 3 3 \%}$ & $\mathbf{- 5 2 . 5 0 \%}$ & $\mathbf{0 . 6 4}$ & $\mathbf{0 . 8 6}$ & $\mathbf{1 6 . 7 1 \%}$ \\
\hline Greenblatt (Quarterly) & $12.45 \%$ & $-58.63 \%$ & 0.47 & 0.78 & $29.03 \%$ \\
\hline S\&P500 (All Three) & $14.58 \%$ & $-54.10 \%$ & 0.61 & 0.91 & $23.64 \%$ \\
\hline
\end{tabular}

In the worst case scenario, Buffett's quarterly investment strategy provides the lowest return, but also the highest Sharpe and Sortino ratios, and the lowest standard deviation. Still, Buffett's quarterly method handsomely beats S\&P 500 for all three different rebalancing frequencies.

According to statistics compiled by the Pew ChariExhibit Trusts (Mennis, 2017), the highest 10-year return among all public pension systems in the nation was $8.30 \%$ for the 10 -year period ending in 2016 ; and $6.58 \%$ was the average return of all of the public pension systems in an Excel data file titled, "Pew Pension Investment Data". As we notice in Exhibit 10, from examining the investment period of January $1^{\text {st }}, 2006$ to December $31^{\text {st }}, 2015$, we found that three out of five investment strategies that we examined outperformed the best public pension system in the nation, and four out of five investment systems did better than the average public pension system.

Exhibit 10: Comparison of Five investment Strategies with Returns from Public Pension Systems (PEW), Using Yearly Rebalance Frequency

\begin{tabular}{|l|l|l|l|l|l|}
\hline Strategy & Annualized Return & \multirow{2}{*}{ Max. Drawdown } & \multicolumn{3}{|l|}{ Risk Statistics (Monthly Period) } \\
\cline { 4 - 6 } & & & Sharpe & Sortino & S. D. \\
\hline NoOtcAdr & $7.03 \%$ & $-60.54 \%$ & 0.38 & 0.52 & $19.19 \%$ \\
\hline Buffett & $8.45 \%$ & $-38.80 \%$ & 0.56 & 0.73 & $12.93 \%$ \\
\hline Fed & $8.47 \%$ & $-52.72 \%$ & 0.45 & 0.61 & $18.74 \%$ \\
\hline Greenblatt & $11.59 \%$ & $-56.64 \%$ & 0.56 & 0.77 & $21.68 \%$ \\
\hline S\&P500 & $5.08 \%$ & $-57.00 \%$ & 0.33 & 0.42 & $15.80 \%$ \\
\hline
\end{tabular}

Note: The study period of $1 / 1 / 2006-12 / 31 / 2015$

\section{Conclusion and Future Implications}

In this paper, we examine five investment strategies which are known to be easy to implement by non-investment professionals. The reason that we have chosen these investment strategies is that there is little cost to implement any of these strategies, and they require little maintenance. There are other strategies which can be also used by sophisticated professionals who aspire to develop an automated investing system. Besides the market index-type investment strategies such as S\&P 500 or NoOtcAdr, readers may investigate any index-based investment strategies as alternatives. By adopting the testing methodologies that we used in this paper, readers may explore other investment possibilities by subscribing services and modifying them for their own needs based on their return and risk preferences. As more employers are gradually moving employees to 401(k)-style retirement plans, these types of research findings add much value to society by assisting common working men and women in making sound decisions on where to park their hard-earned savings.

The authors of this paper propose more researchers to get involved in these types of research projects. The researchers may explore other easy-to-implement investment strategies not covered in this paper or extend the ideas in this paper to make investing processes for the common men and women even simpler.

\section{References}

Allentuck, A. (2017), “ Robo advisors are taking the emotion out of wealth management --- but not everyone 
thinks that's a good thing', Financial Post (May 29, 2017). Available at: $\mathrm{http}$ //business.financialpost.com/personal-finance/managing-wealth/robo-advisors-are-taking-the-emotionout-of-wealth-management-but-not-everyone-thinks-thats-a-good-thing.

Conover, C. M., G. R. Jensen, R. R. Johnson, and J. M. Mercer. (2008a). "Sector Rotation and Monetary Conditions", The Journal of Investing 17 (1) (Spring): 34-46.

Conover, C. M., G. R. Jensen, R. R. Johnson, and J. M. Mercer. (2008b). "Sector Rotation and Monetary Conditions", CFA Digest (August): 66-68.

Dabrowski, T. and J. Klingner (2017a). "Illinois owes over \$250 billion in pension debt", Illinois Policy (June 1, 2017). Available at: https://www.illinoispolicy.org/moodys-downgrades-illinois-to-1-notch-above-junkwarns-state-pension-liabilities-top-250b/.

Dabrowski, T. and J. Klingner (2017b). "Pennsylvania introduces 401(k)-style plans for government workers", Illinois Policy (June 12, 2017). Available at: https://www.illinoispolicy.org/pennsylvania-introduces-401kstyle-plans-for-government-workers/.

Dagnino, G. (2001). Profiting in Bull or Bear Markets. McGraw-Hill, New York.

Doorn, P. V. (2015). "When the stock market last crashed, these sectors fared best", Market Watch (August 24, 2015). Available at: http://www.marketwatch.com/story/when-the-stock-market-last-crashed-these-sectorsfared-best-2015-08-21.

Dunkelberger, L. (2017). "Florida state workers to see pay raise, pension changes", PalmBeachPost.com. (May 1 ,

2017). Available at: http://www.palmbeachpost.com/news/state--regional-govt--politics/florida-state-workerssee-pay-raise-pension-changes/pkhE3ugsrMnftprLTHLTCL/.

Eggert, D. (2017a). "Michigan leads effort to shift workers away from pensions", apnews.com (February 5, 2017). Available at: https://apnews.com/962432c44c8743c5b305b8f04902633e/michigan-leads-effort-shiftworkers-away-pensions.

Eggert, D. (2017b). "New teachers would default to 401(k) under compromise plan", U.S.News (June 8, 2017). Available at: https://www.usnews.com/news/best-states/michigan/articles/2017-06-08/snyder-gop-leadershave-tentative-deal-on-teacher-pensions.

Federal Reserve Economic Data (FRED). (2017). Available at: https://fred.stlouisfed.org/.

Fedfunds. (2017). Available at: https://fred.stlouisfed.org/series/FEDFUNDS.

Fortune Magazine (1999), "Buffett and Loomis 1999". Available at https://archive.fortune.com/magazines/fortune/fortune_archive/1999/11/22/269071/index.htm

Fortune Magazine (2001), "Buffett and Loomis 2001". Available at https://archive.fortune.com/magazines/fortune/fortune archive/2001/12/10/314691/index.htm

Frankel. M. (2017). "Warren Buffet Just Revealed the Best Investment Most People Can Make", The Motley Fool (February 20, 2017). Available at: https:/www.fool.com/investing/2017/02/26/warren-buffett-just-revealedthe-best-investment-m.aspx.

Gillies, T. (2017). "Warren Buffett says index funds make the best retirement sense 'practically all the time", CNBC (May 14, 2017). Available at: http://www.cnbc.com/2017/05/12/warren-buffett-says-index-fundsmake-the-best-retirement-sense-practically-all-the-time.html.

Greenblatt, J. (1999). You can be a stock market genius: Uncover the secret hiding places of stock market profits.

Touchstone.

Greenblatt, J. (2017a). Wikipedia. Available at: https://en.wikipedia.org/wiki/Joel_Greenblatt.

Greenblatt, J. (2017b). Magic Formula Investing. Available at: https://www.magicformulainvesting.com/.

Iasevoli, B. (2017). "Michigan may soon enroll teachers in 401(k)-type retirement plans", Education Week (June 10, 2017). Available

http://blogs.edweek.org/edweek/teacherbeat/2017/06/michigan_may_soon_enroll_teach.html

Kashkari, N. (2017). "Why I dissented again", minneapolisfed.org (June 16, 2017). Available at: https://minneapolisfed.org/news-and-events/messages/why-i-dissented-again.

Kraft, A. (2016). "Apps that make investing easy: Acorns, Betterment, Robinhood, Stash", MagnifyMoney (September 19, 2016). Available at: http://www.magnifymoney.com/blog/reviews/investing-apps-acornsstash-betterment-robinhood884245432/.

La Roche, J. (2017). "Why high-cost money managers aren't worried about the passive investing boom", Yahoo!Finance (June 11, 2017). Available at: https://finance.yahoo.com/news/high-cost-money-managersarent-worried-passive-investing-boom-142636185.html.

Lobosco, J. (2017). “Are public pensions a thing of the past for young workers?”, CNN Money (June 13, 2017). Available at: http://money.cnn.com/2017/06/13/retirement/pennsylvania-pension-reform/index.html?iid=hpstack-dom.

Mennis, G. (2017). "State public pension funds increase use of complex investments", The PEW ChariExhibit Trusts (April 12, 2017). Available at: http://www.pewtrusts.org/en/research-and- 
analysis/reports/2017/04/state-public-pension-funds-increase-use-of-complex-investments.

Mislinski, J. (2017). "Market Cap to GDO: An Updated Look at the Buffett Valuation Indicator", Advisor Perspectives, $\quad$ Inc. (June 20 2017). Available https://www.advisorperspectives.com/dshort/updates/2017/05/02/market-cap-to-gdp-an-updated-look-atthe-buffett-valuation-indicator.

MSCI (2014). "MSCI Cyclical and Defensive Sectors Indexes Methodology", msci.com (June 2014). Available at: https://www.msci.com/documents/10199/1283513/MSCI_Cyclical_and_Defensive_Sectors_Indexes_Meth odology Jun14.pdf/f05126ab-65f6-4f39-b9d2-ad031858475a.

Oosting, J. and M. Gerstein (2017). "Legislature OKs pension reform over teacher protest", The Detroit News (June 15, 2017). Available at: http://www.detroitnews.com/story/news/politics/2017/06/15/michigan-senateapproves-pension-reform/102887854/.

Pruitt, G. (2016). Ultimate Algorithmic trading system toolbox: Using today's technology to help you become a better trader. Wiley \& Sons, Inc., New Jersey.

Stockcharts.com. (2017). "Average directional index (ADX)", Stockcharts.com. Available at: $\mathrm{http}: / /$ stockcharts.com/school/doku.php?id=chart_school:technical_indicators:average_directional_index_ad

Suzman, R. and J. Beard (2015). "Living longer", Global Health and Aging (January 22, 2015). Available at: https://www.nia.nih.gov/research/publication/global-health-and-aging/living-longer.

Thompson, C. (2017). "Pa. House passes pension plan changes, sending bill to Gov. Wolf's Desk", pennlive.com (June 8, 2017). Available at: http://www.pennlive.com/news/2017/06/pa house passes pension plan c.html.

VanMetre, B. (2014). "States on the move: 401(k)-style pension reform in Georgia", Illinois Policy (November 13, 2014). Available at: https://www.illinoispolicy.org/states-move-401k-style-pension-reform-georgia/.

Verhage, J. and K. Chiglinksy (2017). "Ventures into robot advising in main street push", Wealth Management.com (June 6, 2017). Available at: http://www.wealthmanagement.com/technology/century-oldtiaa-ventures-robo-advising-main-street-push.

APPENDIX

\section{P123's High-level Computer Programming Code for Investment Strategies}

(1) S\&P 500 strategy

(2) No OTC \& No ADR (NoOtcAdr) strategy

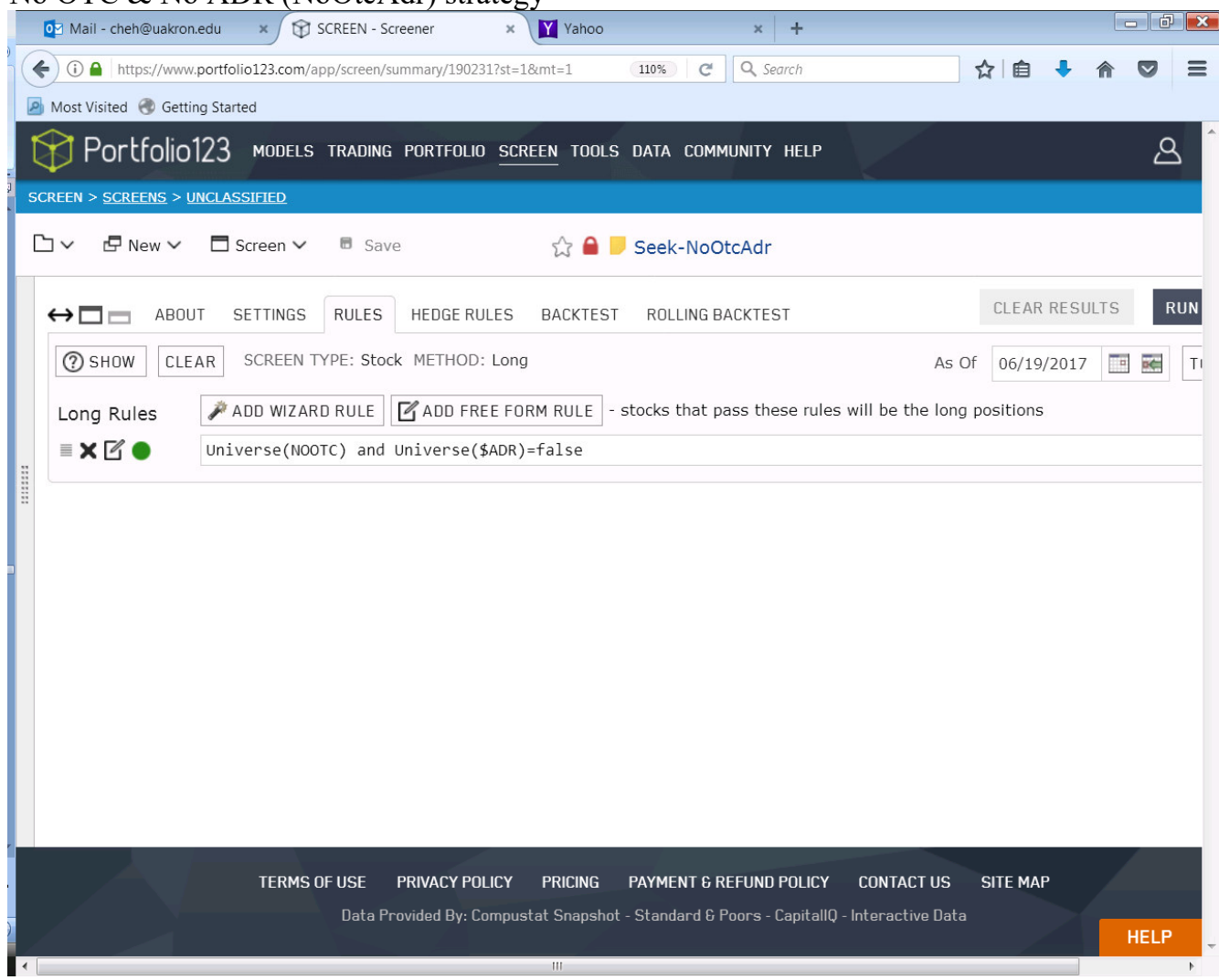


(3) Warren Buffett's stock market indicator-based strategy

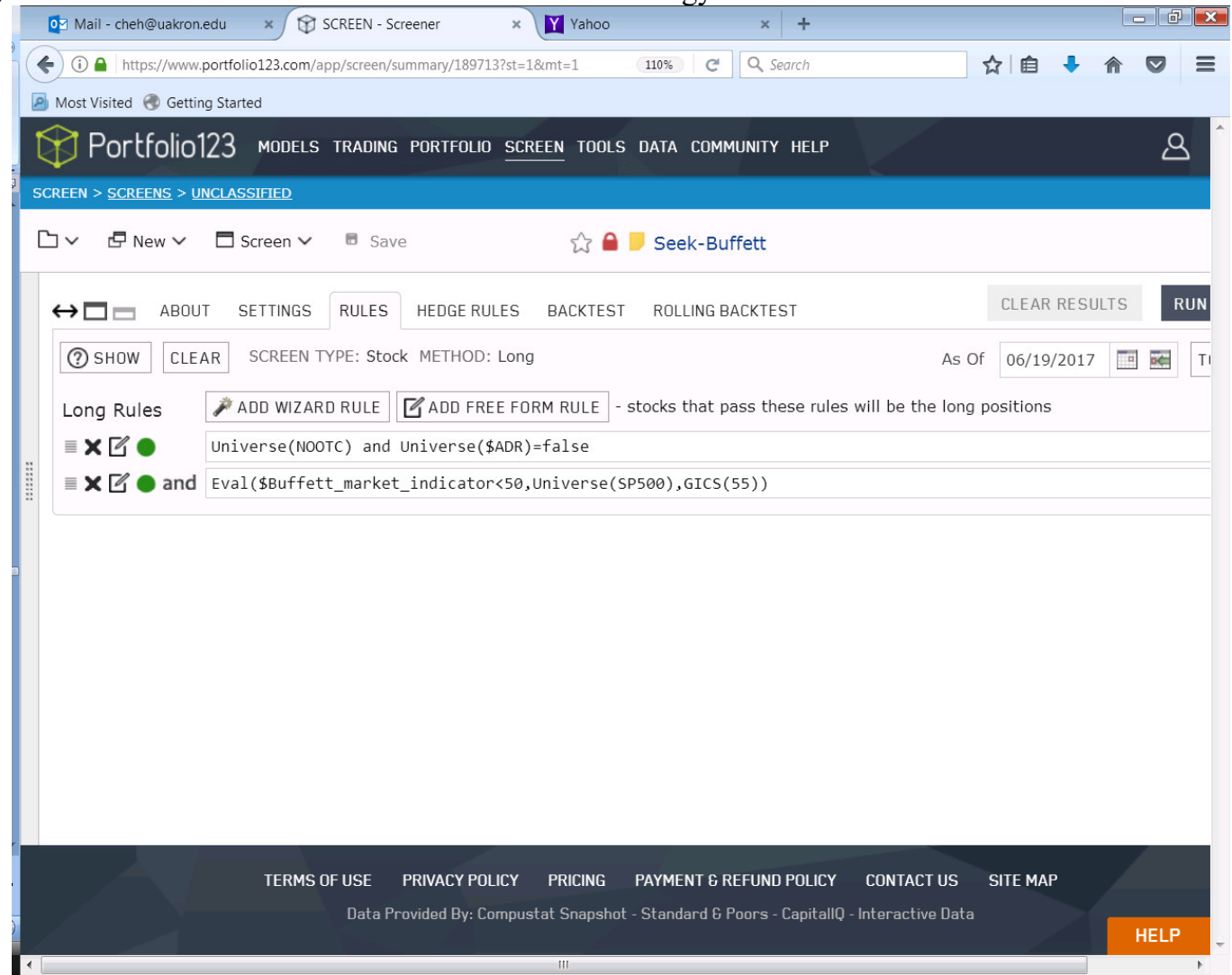

(4) Federal Reserve Bank's monetary policy-based strategy

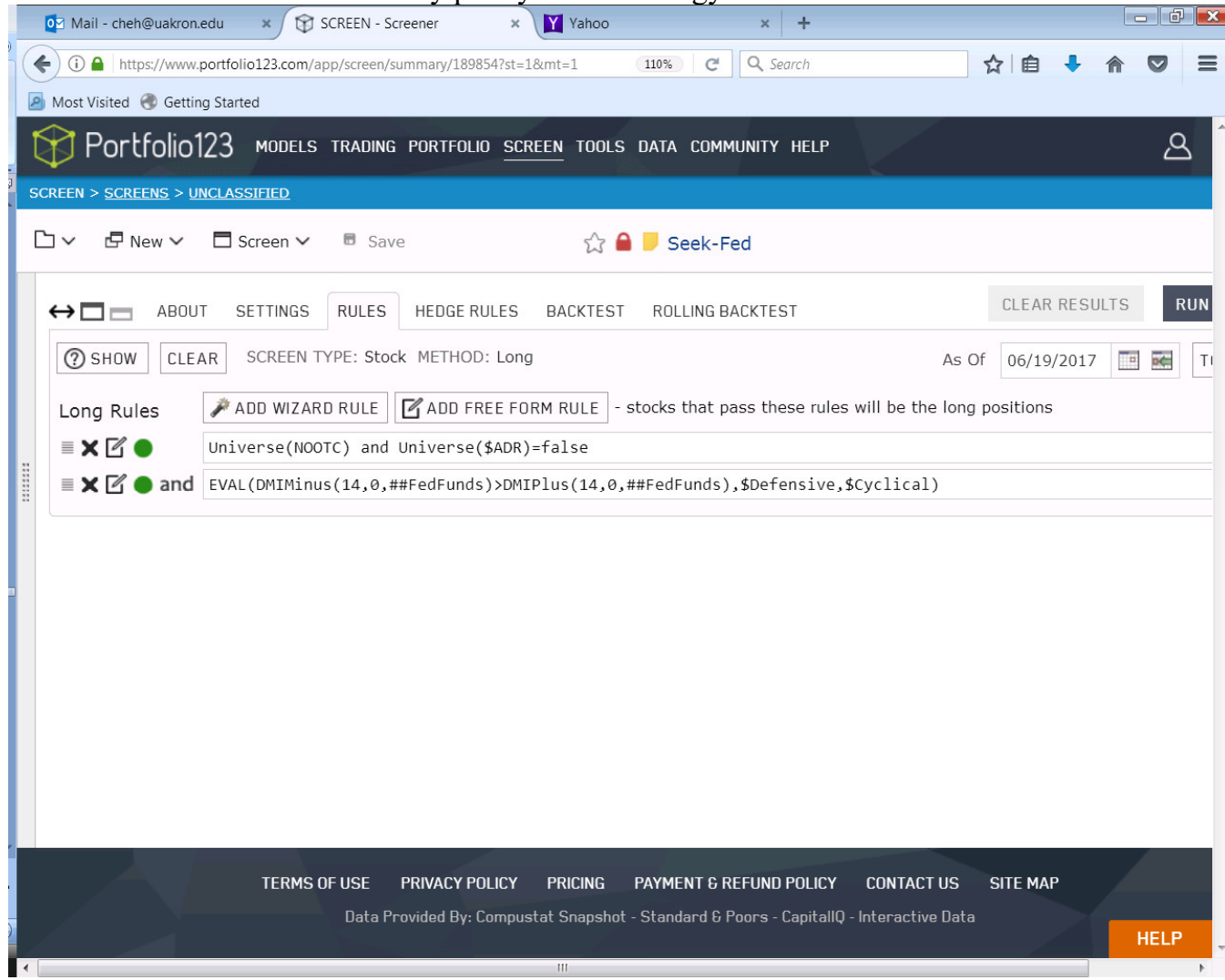


(5) Joel Greenblatt's magic formula strategy

Panel A: Settings (Note: Max No. Stocks, 15; Ranking System, All-Stars: Greenblatt)

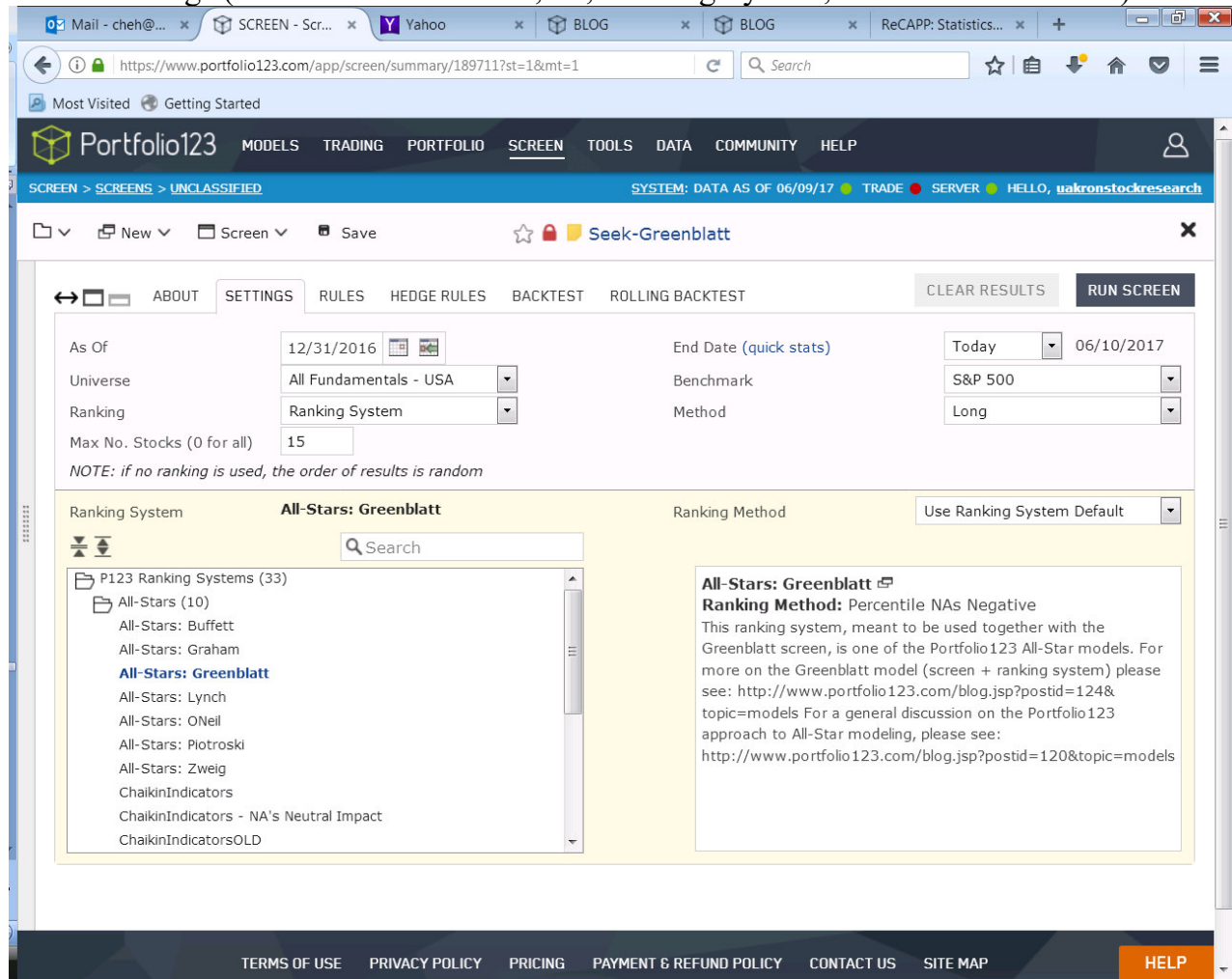

Panel B: Rules

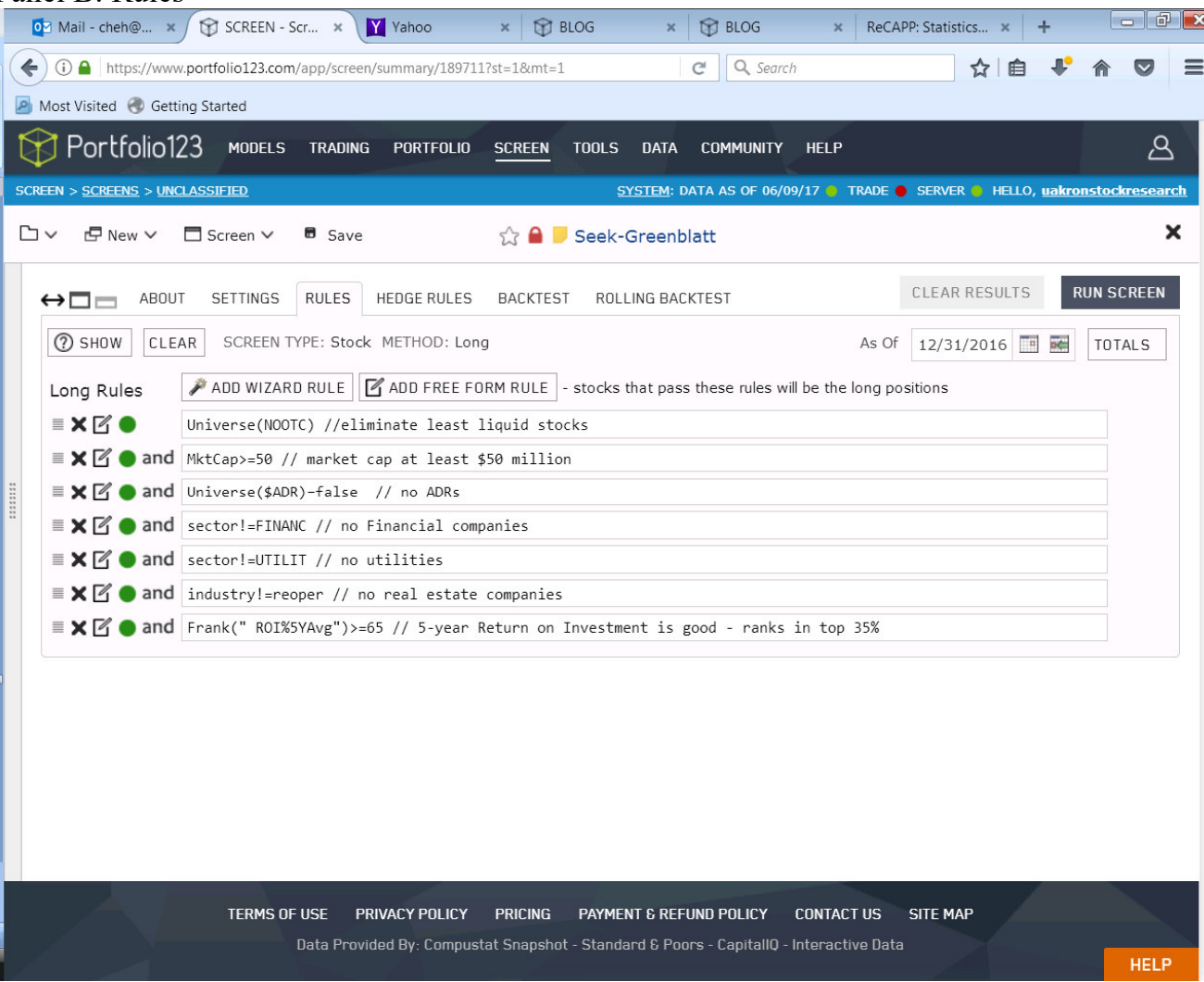


Panel C: Chart with Yearly Rebalance Frequency

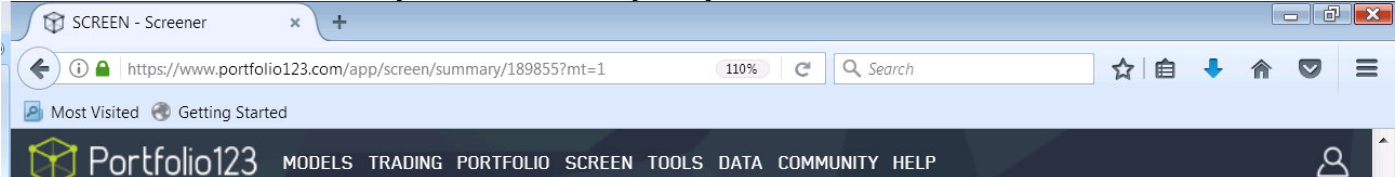

8 Portfolio123 models trading PORTFOLIO SCREen tOols DATA COMMUNITY helP

$\leftrightarrow$ BACKTEST RESULTS

Statistics

\begin{tabular}{|c|c|c|c|c|c|c|c|c|c|c|}
\hline & \multirow{2}{*}{$\begin{array}{l}\text { Total } \\
\text { Return }\end{array}$} & \multirow{2}{*}{$\begin{array}{l}\text { Annualized } \\
\text { Return }\end{array}$} & \multirow{2}{*}{$\begin{array}{l}\text { Max } \\
\text { Drawdown }\end{array}$} & \multicolumn{7}{|c|}{ Risk Statistics (MONTHLY Period) } \\
\hline & & & & Sharpe & Sortino & StdDev & CorrelBench & R-Squared & Beta & Alph \\
\hline Screen & $1,415.92 \%$ & $16.30 \%$ & $-60.76 \%$ & 0.73 & 1.05 & $21.06 \%$ & 0.71 & 0.51 & 0.97 & 13. \\
\hline S\&P 500 & $83.17 \%$ & $3.42 \%$ & $-57.00 \%$ & 0.17 & 0.22 & $15.35 \%$ & - & - & - & - \\
\hline
\end{tabular}

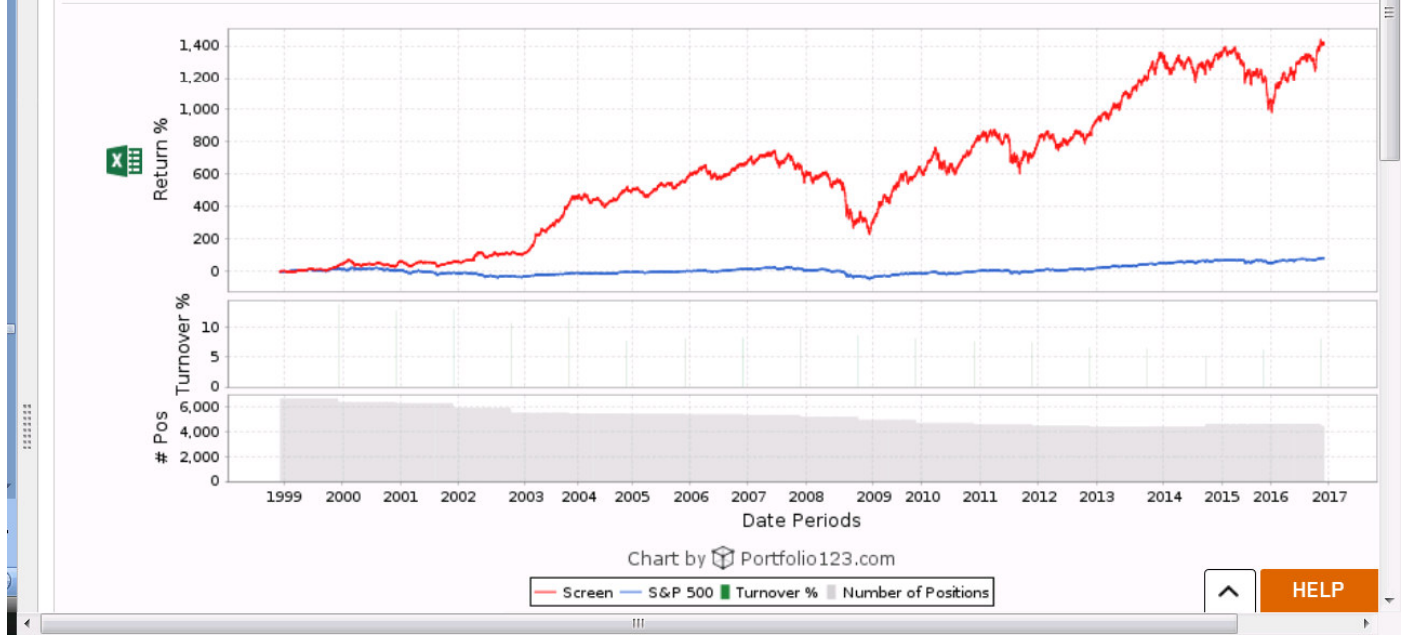

